\title{
Effect of barium doping on electrical and electromechanical properties of (1-x)(Na $\left.\mathrm{Na}_{0.5} \mathrm{Bi}_{0.5}\right) \mathrm{TiO}_{3}-\mathrm{xBaTiO}_{3}$
}

\author{
Mohmmed Mesrar ${ }^{1, *}$, Tajdine Lamcharfi ${ }^{1}$, Nor-Said Echatoui ${ }^{1}$, Farid Abdi ${ }^{1}$, Fatima Zahra Ahjyaje ${ }^{2}$ \\ and Mustapha Haddad ${ }^{3}$ \\ ${ }^{1}$ Signals, Systems and Components Laboratory (LSSC), USMBA, FST-Fez, Imouzzer road B.P 2202, Morocco \\ ${ }^{2}$ Laboratory of Materials, Natural Substances, Environment and Modeling (LMSNEM), Polydisciplinary \\ Faculty of Taza, USMBA, Imouzzer road B.P 2202, Morocco \\ ${ }^{3}$ Spectrometry, Materials and Archaeomaterials Laboratory (LASMAR)
}

\begin{abstract}
The effect of Barium doping is studied on ferroelectric properties of $(1-\mathrm{x})\left(\mathrm{Na}_{0.5} \mathrm{Bi}_{0.5}\right) \mathrm{TiO}_{3}-\mathrm{xBaTiO}_{3}$ with $(\mathrm{x}=0.00 ; 0.03 ; 0.05 ; 0.06 ; 0.07 ; 0.08$ and 0.10$)$ prepared through solid state sintering route. $\mathrm{X}$-ray diffraction along with Rietveld refinement revealed a gradual change in crystal structure from rhombohedral to tetragonal with increasing BaTiO3 doping in the compound. SEM images have shown a uniform distribution of grains and change in grain size with $\mathrm{BaTiO}_{3}$ concentration. Dielectric and dispersive studies have been carried out. The rhombohedral distortion of the unit cell slightly increased and ferroelectric transition temperature, $\mathrm{T}_{\mathrm{m}}$ decreased with the increase of Barium content and all compositions of $(1-\mathrm{x})\left(\mathrm{Na}_{0.5} \mathrm{Bi}_{0.5}\right) \mathrm{TiO}_{3}$ - $\mathrm{XBaTiO}_{3}$ ceramic materials reveal diffuse phase transition that is marked by a strong frequency dispersion of the permittivity which would be related with the cation disorder in the A site of the unit cell. Combined impedance and electrical propriety were used to analyze impedance data. The electromechanical parameters were calculated from the resonant and anti-resonant frequencies from the evolution of the permittivity according to the frequency plots. The electromechanical coefficients for $(1-\mathrm{x})\left(\mathrm{Na}_{0.5} \mathrm{Bi}_{0.5}\right) \mathrm{TiO}_{3}-\mathrm{xBaTiO}_{3}$ with all compositions were found to be much larger than that of pure $\mathrm{Na}_{0.5} \mathrm{Bi}_{0.5} \mathrm{TiO}_{3}$.
\end{abstract}

Keywords: Dielectric properties; Resonant frequency; Anti-resonant frequency; Complex impedance plots.

\section{Introduction}

The investigation of the electrical properties of $(1-\mathrm{x})\left(\mathrm{Na}_{0.5} \mathrm{Bi}_{0.5}\right) \mathrm{TiO}_{3}-\mathrm{xBaTiO}_{3}$ had been and still is a very important research problem because of its scientific importance and the difficulty of explainning the behavior fundamental. The electrical resistance and ferroelectric transition temperature can be controlled effectively by doping in A-site between $(\mathrm{Na} / \mathrm{Bi})$ and $\mathrm{Ba}$ ions ${ }^{1}$. Barium titanate and its related compounds have been widely used in the manufacture of ceramic capacitors and resistors. Since its discovery, $\mathrm{BaTiO}_{3}$ has been used as a high permittivity capacitor material because of its high dielectric constant ${ }^{2}$. Variation in chemical composition or thermal treatment in these ceramics led to quite drastic changes in physical properties while retaining substantially piezoelectric properties ${ }^{3}$. NBT has a relatively large remanent polarization $\left(\operatorname{Pr}=38 \mu \mathrm{C} / \mathrm{cm}^{2}\right)$, exhibiting a high Curie temperature $\left(\mathrm{T}_{\mathrm{c}}=320^{\circ} \mathrm{C}\right)$ and a high coercive field $\left(\mathrm{E}_{\mathrm{c}}=73 \mathrm{kV}\right.$ $/ \mathrm{cm})$ at room temperature, also presents a relatively large conductivity ${ }^{4}$. Jones et al reported at ambient temperature, which this compounds are

*Corresponding author: Mohammed Mesrar

Email address: mohammed.mesrar@usmba.ac.ma DOI: http://dx.doi.org/10.13171/mjc8319050908mm rhombohedral and described with R3c symmetry with polar cation displacements combined with anti-phase rotations of oxygen octahedral 5 . Dielectric behavior of the NBT-based system is ferroelectric at room temperature, on increasing temperature ferroelectric to anti-ferroelectric phase transition has been reported at $\sim 220^{\circ} \mathrm{C}$ defined as $\mathrm{T}_{\mathrm{d}}$, the second transition occurs around $320^{\circ} \mathrm{C}$ abbreviated as $\mathrm{T}_{\mathrm{m}}$ corresponding with to a transition from the anti-ferroelectric to paraelectric phase ${ }^{6}$. The aim of the present investigation is to apply the variable- frequency techniques of impedance spectroscopy to Barium doped $\left(\mathrm{Na}_{0.5} \mathrm{Bi}_{0.5}\right) \mathrm{TiO}_{3}$ to probe some of the above aspects and seek to obtain the correlation between the disorder on site $\mathrm{A}(\mathrm{Na} / \mathrm{Bi})$ and relaxor behavior of these compositions.

\section{Experimental Details}

Ceramic samples were prepared by applying the conventional ceramic sintering technique. The samples were fabricated using grade (99.99\% pure) $\mathrm{Na}_{2} \mathrm{CO}_{3}, \mathrm{Bi}_{2} \mathrm{O}_{3}, \mathrm{TiO}_{2}$ and $\mathrm{BaCO}_{3}$. The investigated compounds are $(1-\mathrm{x})\left(\mathrm{Na}_{0.5} \mathrm{Bi}_{0.5}\right) \mathrm{TiO}_{3}-\mathrm{xBaTiO}_{3}$ with

\footnotetext{
Received February 10, 2019 Accepted March 23, 2019 Published May 9, 2019
} 
$(\mathrm{x}=0.00 ; 0.03 ; 0.05 ; 0.06 ; 0.07 ; 0.08$ and 0.10 ). Stochiometric amounts were weighed and homogenized in agate vessel in acetone for $4 \mathrm{~h}$. The obtained mixture was then calcined at $1000^{\circ} \mathrm{C}$ for 4hours. The sintering was carried out at $1100^{\circ} \mathrm{C}$ Xpert-Pro diffractometer with $\mathrm{CuK} \alpha(\lambda=1.5406 \AA)$ radiation at room temperature in the $2 \theta$ range of $10^{\circ}$ to $100^{\circ}$ at a scan step of $0.02^{\circ} \%$ s. Crystallite sizes and lattice constants were determined from Rietveld refinements of the experimental diffraction data ${ }^{7}$. Raman scattering experiments were performed using a micro Raman spectrometer. Weak-field dielectric properties and dissipation factor $(\tan \delta)$ in temperature range from $40^{\circ} \mathrm{C}$ to $600^{\circ} \mathrm{C}$ and frequency region from $500 \mathrm{~Hz}$ to $1 \mathrm{MHz}$ were studied using an Agilent impedance analyzer. Frequency response analyzer is attached to a computer for programmed measurements. The real part $Z^{\prime}$ and imaginary part $\mathrm{Z}^{\prime \prime}$ of impedance were collected immediately from the impedance meter.

\section{Theory}

AC impedance techniques are generally used to characterize electrical properties of materials. Data may be examined in terms of four possible complex admittance functions, the complex impedance $\left(Z^{*}\right)$, complex permittivity $\left(\mathcal{E}^{*}\right)$, complex electric modulus $\left(\mathrm{M}^{*}\right)$ and the complex admittance $\mathrm{A}^{*}\left(\text { or } \mathrm{Y}^{*}\right)^{8}$.

$$
\begin{aligned}
& Z^{*}=Z^{\prime}-j Z^{\prime \prime}=\left(Y^{*}\right)^{-1}=R_{\mathrm{s}}-\frac{1}{\mathrm{j} \omega \mathrm{Cs}} \\
& \varepsilon *=\varepsilon^{\prime}-\mathrm{j} \varepsilon^{\prime \prime} \\
& M^{*}=M^{\prime}+\mathrm{j} M^{\prime \prime}=\mathrm{j} \omega \varepsilon_{0} Z^{*}
\end{aligned}
$$

With $\omega$ is the angular frequency $(2 \pi \mathrm{f}), \mathrm{C}_{0}$ is the geometrical capacitance of the sample, $\varepsilon_{0}$ designates the permittivity of free space $\left(8,854 * 10^{-12} \mathrm{~F} / \mathrm{m}\right)$. Complex impedance and Cole-Cole plot are utilized to distribute out the contribution of grain and grain boundary effects of the ceramics ${ }^{*}$ ) ${ }^{9}$. With supplementary use of complex electric modulus formalism, the inhomogeneous character of polycrystalline ceramics can be examined into. The grain boundary and bulk effects may be detected from the impedance data. The temperature dependence of grain boundary influences and bulk capacitance can then be analyzed. In consequence, to investigate and understand the experimental data, it is essential to have a model. The equivalent circuit gives a realistic description of the electrical behavior of the compound ${ }^{10}$.

\section{Results and discussion}

The X-ray diffraction patterns of $(1-\mathrm{x})\left(\mathrm{Na}_{0.5} \mathrm{Bi}_{0.5}\right) \mathrm{TiO}_{3}-\mathrm{xBaTiO}_{3} \quad$ ceramics are illustrated in Figure 1(a). All the samples show a pure perovskite structure phase and no secondary phase could be detected, indicating that $\mathrm{Ba}^{2+}$ has successfully diffused into the $\mathrm{Na}_{0.5} \mathrm{Bi}_{0.5} \mathrm{TiO}_{3}$ lattice to form a solid solution ${ }^{11,12}$. A fine scanning of (202) reflection in the $2 \theta$ ranges $46^{\circ}-47^{\circ}$ is displayed in Figure 1(b) accompanied by splitting peaks, typical of tetragonal phase. These peaks are indexed as $(200)_{\mathrm{R}}$ and $(002)_{\mathrm{T}}$ corresponds to rhombohedral and tetragonal phases, respectively and confirmed the existence of morphotropic transformation phase (MPB) in the composition range of $\mathrm{x}=0.05 \sim 0.07$, which is in good agreement with the literature ${ }^{13,14}$.

The structure was also verified with Rietveld refinement of X-ray data (see Figure 2), which shows a rhombohedral structure with R3c space group symmetry and lattice parameters are $(\mathrm{a}=$ 5.4917 $, \quad c=13.4773 \AA, \alpha=90, \beta=90, \gamma=$ 120 and $V=352.004 \AA^{3}$, (hexagonal axes)). As x (i.e. the concentration of $\mathrm{BaTiO}_{3}$ ) increases, a tetragonal phase develops and increases continuously. At $\mathrm{x}=0.08$, the ceramic transforms to the pure tetragonal phase. Fractional atomic coordinates have been tabulated in Table.1. The refined anisotropic displacement factors $\mathrm{Uij}$ for the $\mathrm{A}$ and $\mathrm{B}$ sites are exhibit in Table.2. For the A site, we notice that the thermal factor for $\mathrm{Bi}\left(\mathrm{U}_{11}=0.0359 \AA^{2}\right)$ exhibits a greater anisotropic thermal vibration than $\mathrm{Na}$ $\left(\mathrm{U}_{11}=0.0217 \AA^{2}\right)^{15}$. In addition, the anisotropic displacement factors of the cationic lattice are significantly larger than those of the anionic lattice. Therefore, the existence of local displacements at Asite can be would result in a disordered local structure similar to those reported in Refs ${ }^{16,17,18,19}$.

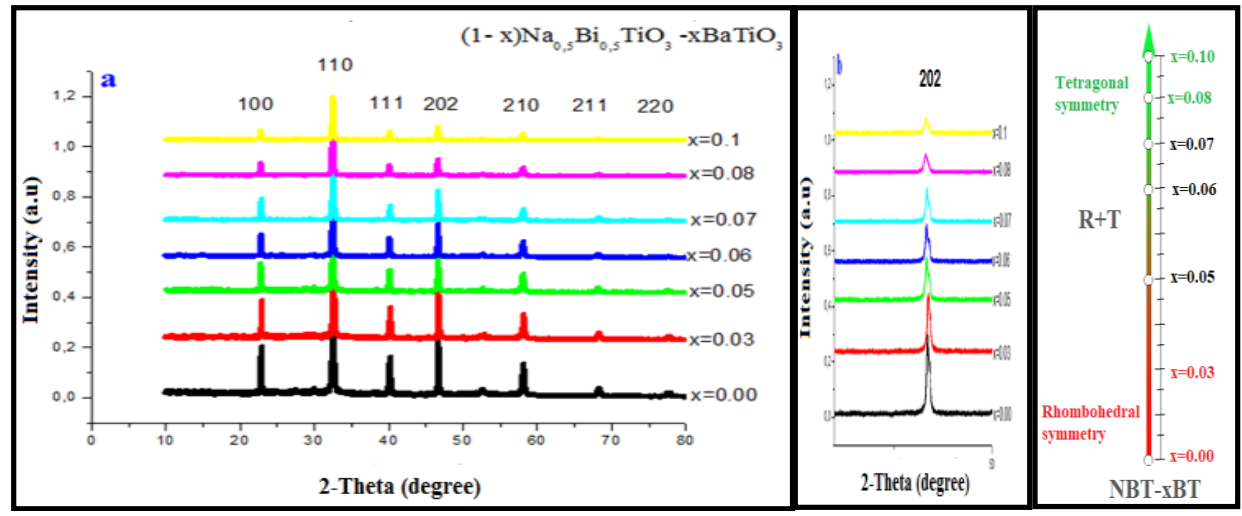

Figure.1 (a) x-ray diffraction pattern of the powder $(1-\mathrm{x})\left(\mathrm{Na}_{0.5} \mathrm{Bi}_{0.5}\right) \mathrm{TiO}_{3}-\mathrm{xBaTiO}_{3}$ (b). Zoom of the peak (202) in the $2 \theta$ range of $46^{\circ}-47^{\circ}$

Table 1. Fractional atomic coordinates. 


\begin{tabular}{|c|c|c|c|c|c|}
\hline (a) Atom species & $\mathbf{X}$ & $\mathbf{y}$ & $\mathbf{Z}$ & $\begin{array}{c}\text { Occ. } \\
\text { Site } \\
\text { wckoff }\end{array}$ \\
\hline $\mathrm{Na}$ & 0.00000 & 0.00000 & 0.26270 & 0.500 & $6 \mathrm{a}$ \\
\hline $\mathrm{Bi}$ & 0.00000 & 0.00000 & 0.26270 & 0.500 & $6 \mathrm{a}$ \\
\hline $\mathrm{Ti}$ & 0.00000 & 0.00000 & 0.00630 & 1.000 & $6 \mathrm{a}$ \\
\hline $\mathrm{O}$ & 0.12600 & 0.08333 & 0.33600 & 1.000 & $18 \mathrm{~b}$ \\
\hline
\end{tabular}

Table 2. The parameters of anisotropic displacement.

\begin{tabular}{|c|c|c|c|c|c|c|}
\hline $\begin{array}{c}\text { (b) Atom } \\
\text { species }\end{array}$ & $\mathbf{U}_{\mathbf{1 1}}$ & $\mathbf{U}_{\mathbf{2 2}}$ & $\mathbf{U}_{\mathbf{3 3}}$ & $\mathbf{U}_{\mathbf{1 2}}$ & $\mathbf{U}_{\mathbf{1 3}}$ & $\mathbf{U}_{\mathbf{2 3}}$ \\
\hline $\mathrm{Na}$ & 0.0217 & 0.0108 & 0.233 & 0.0228 & 0.0359 & 0.0229 \\
\hline $\mathrm{Bi}$ & 0.0359 & 0.0177 & 0.363 & 0.0356 & 0.0348 & 0.0378 \\
\hline $\mathrm{Ti}$ & 0.0108 & 0.0130 & 0.123 & 0.0104 & 0.0118 & 0.0128 \\
\hline $\mathrm{O}$ & 0.0097 & 0.0110 & 0.0108 & 0.0094 & 0.0112 & 0.0107 \\
\hline
\end{tabular}

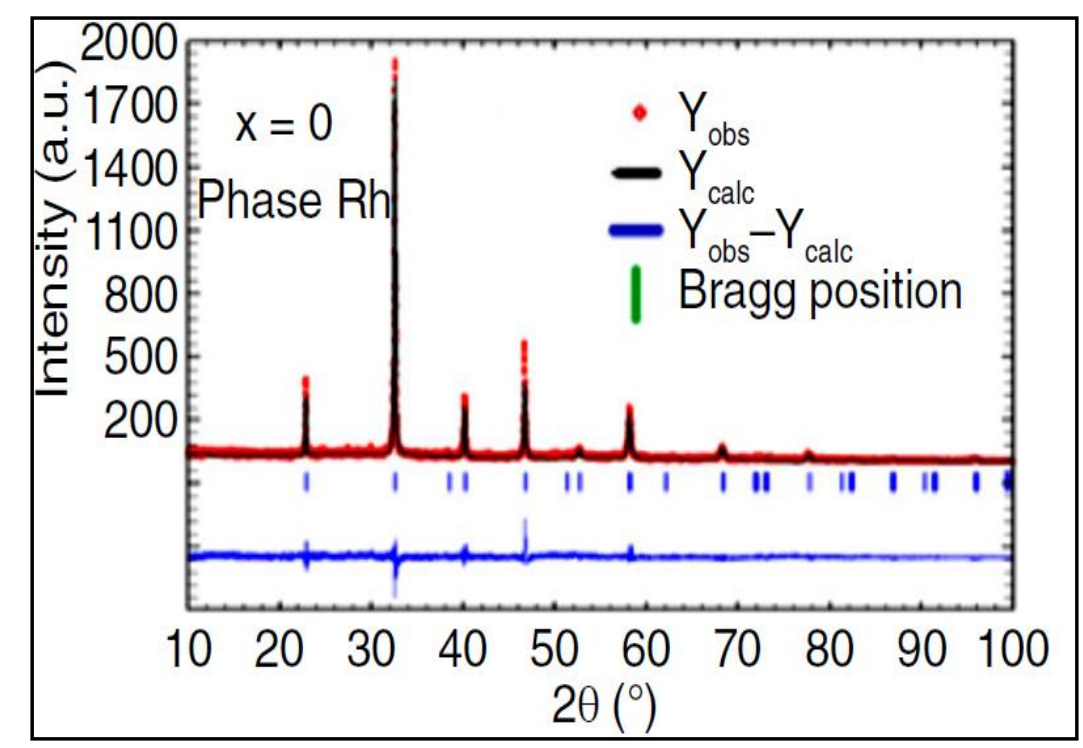

Figure 2. Rietveld refinement for the compound $\mathrm{Na}_{0.5} \mathrm{Bi}_{0.5} \mathrm{TiO}_{3}$ with space group $\mathrm{R} 3 \mathrm{c}$, calcined at $1000{ }^{\circ} \mathrm{C}$

Figure 3 exhibits the Raman spectra of (1$\mathrm{x})\left(\mathrm{Na}_{0.5} \quad \mathrm{Bi}_{0.5}\right) \mathrm{TiO}_{3}-\mathrm{xBaTiO}_{3} \quad$ ceramics for compositions $\quad(\mathrm{x}=0.00 ; 0.03 ; 0.05 ; 0.06$; $0.07 ; 0.08$ and 0.10$)$ at room temperature performed in the range from $100 \mathrm{~cm}^{-1}$ to $1000 \mathrm{~cm}^{-1}$. The vibration modes were displayed in Fig. 3, it can be seen for both $\mathrm{Na}_{0.5} \mathrm{Bi}_{0.5} \mathrm{TiO}_{3}$ and $\mathrm{BaTiO}_{3}$ samples that Raman peaks appear at 137.47; 280.86; 530; 580 and $866 \mathrm{~cm}^{-1}$, while for $\mathrm{BaTiO}_{3}$ based sample Raman peak appear at 274;306;519 and $720 \mathrm{~cm}^{-1}$. All the Raman bands of $\mathrm{Na}_{0.5} \quad \mathrm{Bi}_{0.5} \mathrm{TiO}_{3}$ ceramic have a relatively broad nature because of the polycrystalline characteristics of the samples and disorder due to random occupancy of cation $\mathrm{Na} / \mathrm{Bi} / \mathrm{Ba}$ in site $\mathrm{A}^{20,21 \text {, }}$ 22. The deconvolution of the spectrum of pure NBT with Peakfit software using Gauss and Lorentzian area function, present eight vibration modes as illustrated in details in Figure.4. 


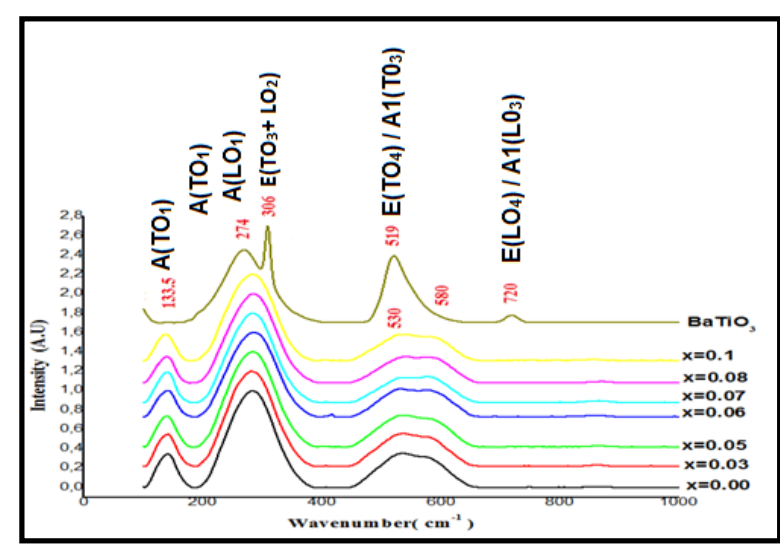

Figure 3. Raman spectra of $(1-\mathrm{x})\left(\mathrm{Na}_{0.5} \mathrm{Bi}_{0.5}\right) \mathrm{TiO}_{3}-$ $\mathrm{xBaTiO}_{3}$ ceramics with different compositions

Figure.5 shows the microstructure of the (1-x) $\left(\mathrm{Na}_{0.5} \mathrm{Bi}_{0.5}\right) \mathrm{TiO}_{3}-\mathrm{xBaTiO}{ }_{3}$ ceramics. Physically, the pellets sintered at $1100^{\circ} \mathrm{C}$ for $4 \mathrm{~h}$ depict more compact and dense structure with of high value of $\left(5.95 \mathrm{~g} / \mathrm{cm}^{3}\right.$.). The SEM images clearly show that there a few pores and no residual incorporated powder on the grains which affect the microstructure which is more compact and well sintered. A characteristic quasi-cubic morphology of the grain with clear grain boundary is obtained in all samples. For the pure NBT ceramic (i.e., $x=0$ ), the grains are large, having a diameter in

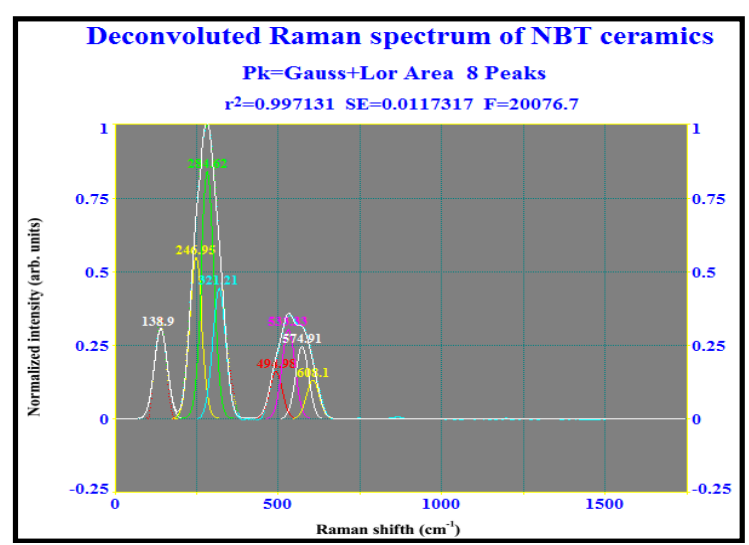

Figure 4. Fitting of the Raman spectra of $\left(\mathrm{Na}_{0.5} \mathrm{Bi}_{0.5}\right) \mathrm{TiO}_{3}$ ceramic by the Gauss+Lor function.

the range of $4 \sim 5 \mu \mathrm{m}$ (see Fig.5 (b)). However, after the introduction of $x=0.03$, the grain size decreases significantly until $2.4 \mu \mathrm{m}$. While the increasing BT content, the grains gradually grew and becomes voluminous, when $\mathrm{x}=0.07$, the average grain size increased up to $4.12 \mu \mathrm{m}$. Furthermore, it presents granulometry high in the range $(x=0.05 \sim 0.07)$, attributed to the coexistence of two phases $(\mathrm{Rh}+\mathrm{T})$ near the morphotropic transformation phase (MPB). For $\mathrm{x}=0.08$ and $\mathrm{x}=0.1$ the substitution generally leads to inhibition of grain growth 23,24
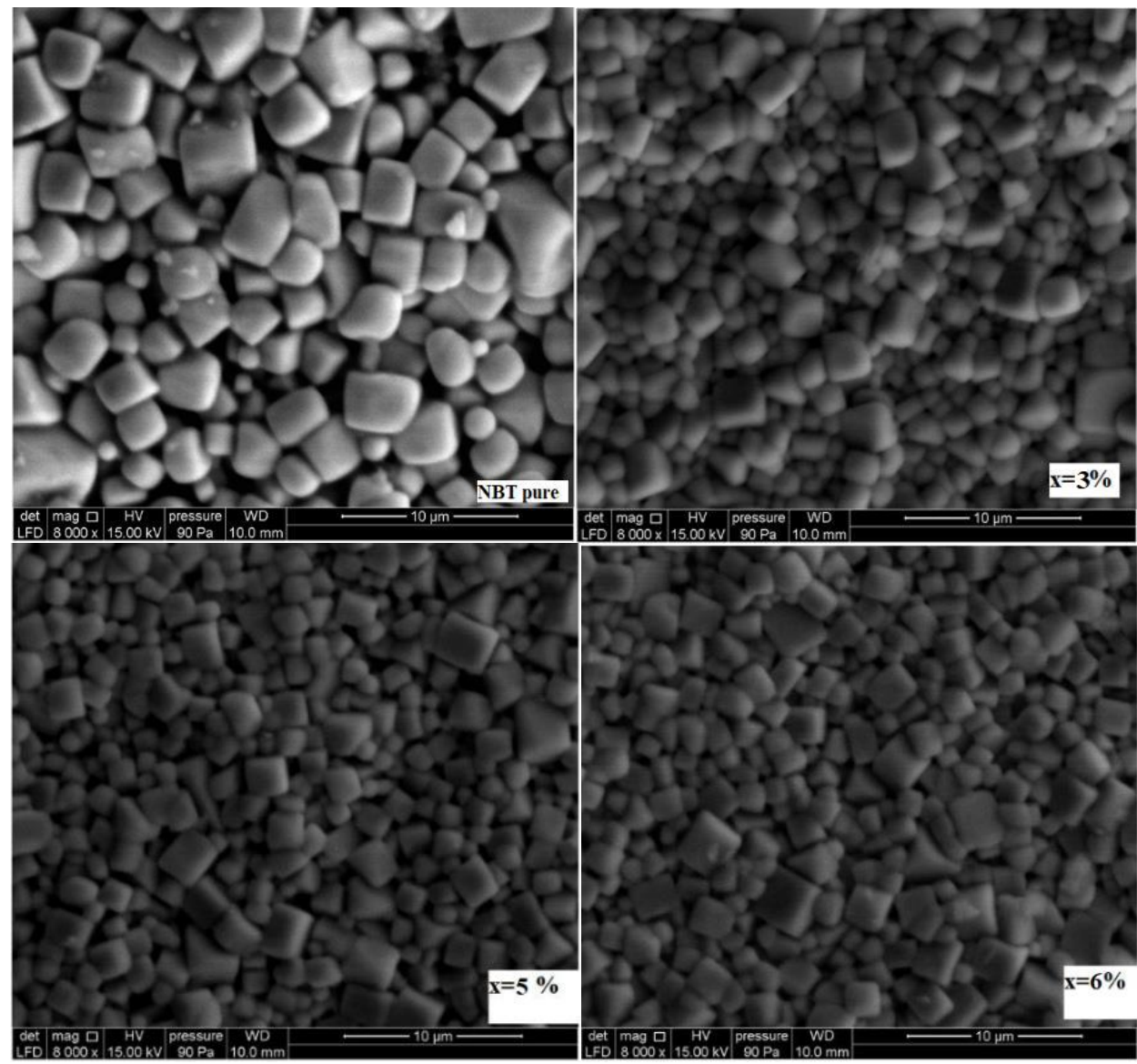

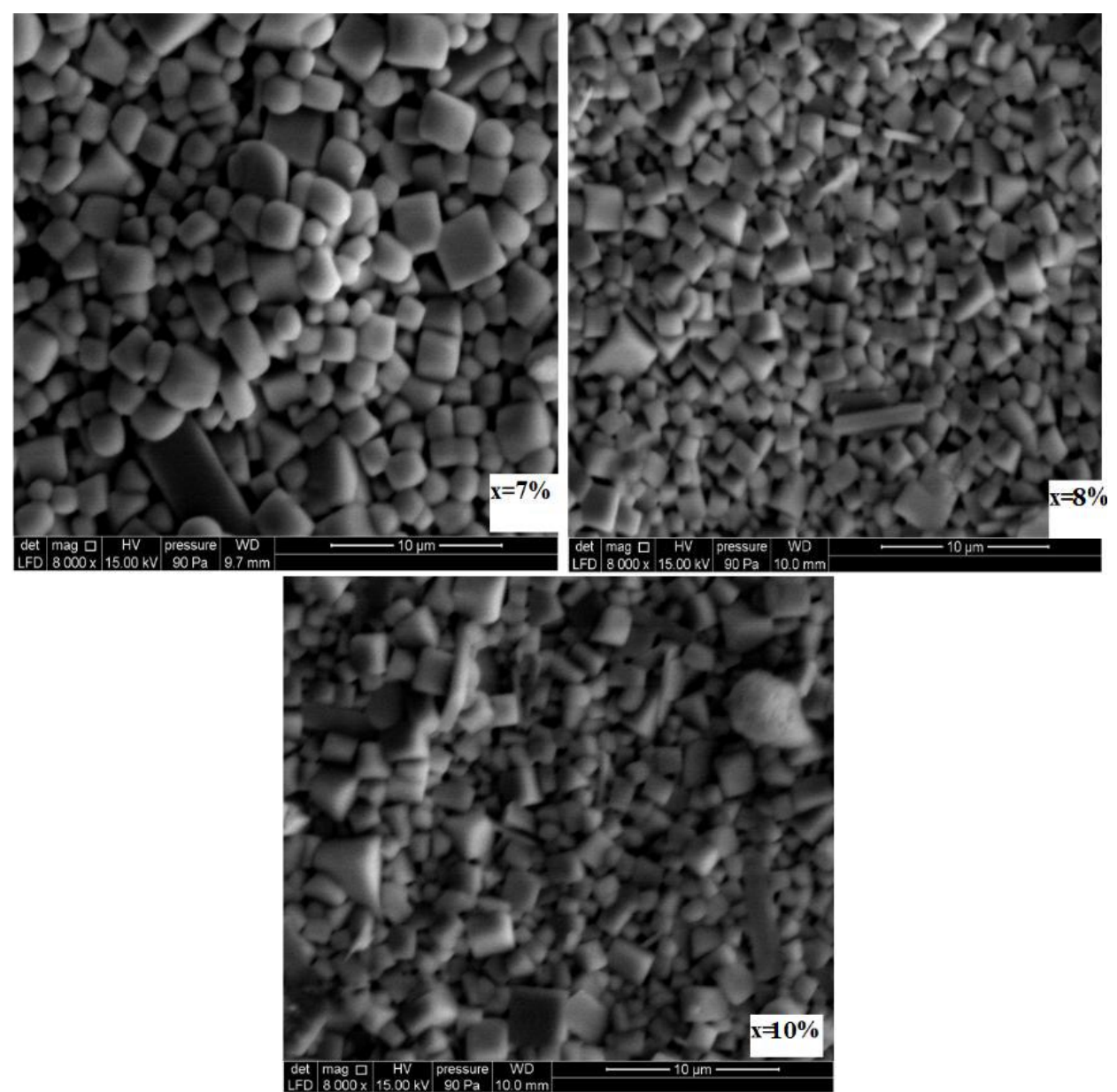

Figure 5 (a). Cross-section SEM images of $(1-\mathrm{x})\left(\mathrm{Na}_{0.5} \mathrm{Bi}_{0.5}\right) \mathrm{TiO}_{3}-\mathrm{xBaTiO}_{3}$ ceramics.

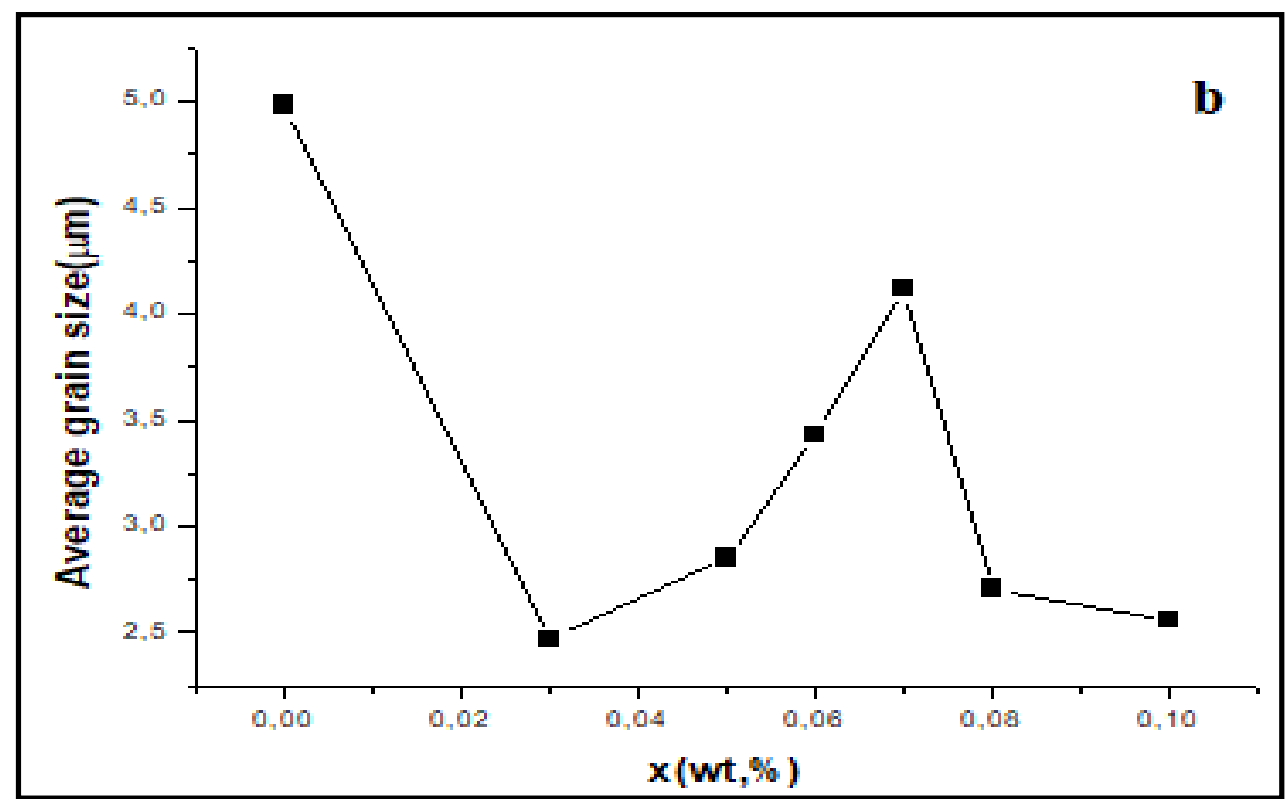

Figure 5 (b). variation of grain size with $\mathrm{x}(\mathrm{wt} . \%)$ in BT

Figure 6 represents the temperature dependence of frequency range of $1 \mathrm{KHz}$ to $50 \mathrm{KHz}$. All the $\mathrm{Er}(\mathrm{T})$ dielectric constant $\operatorname{Er}(\mathrm{T})$ and dielectric loss $(\tan \delta)$ of curves possessed two dielectric anomalies at the $(1-\mathrm{x})\left(\mathrm{Na}_{0.5} \mathrm{Bi}_{0.5}\right) \mathrm{TiO}_{3}-\mathrm{xBaTiO}_{3}(\mathrm{x}=0.00 ; 0.03 ; 0.05$; temperature (Td) and (Tm) (“d” and "m" denote $0.06 ; 0.07 ; 0.08$ and 0.10 ) ceramics, measured in the "shoulder" and "maximum"). 

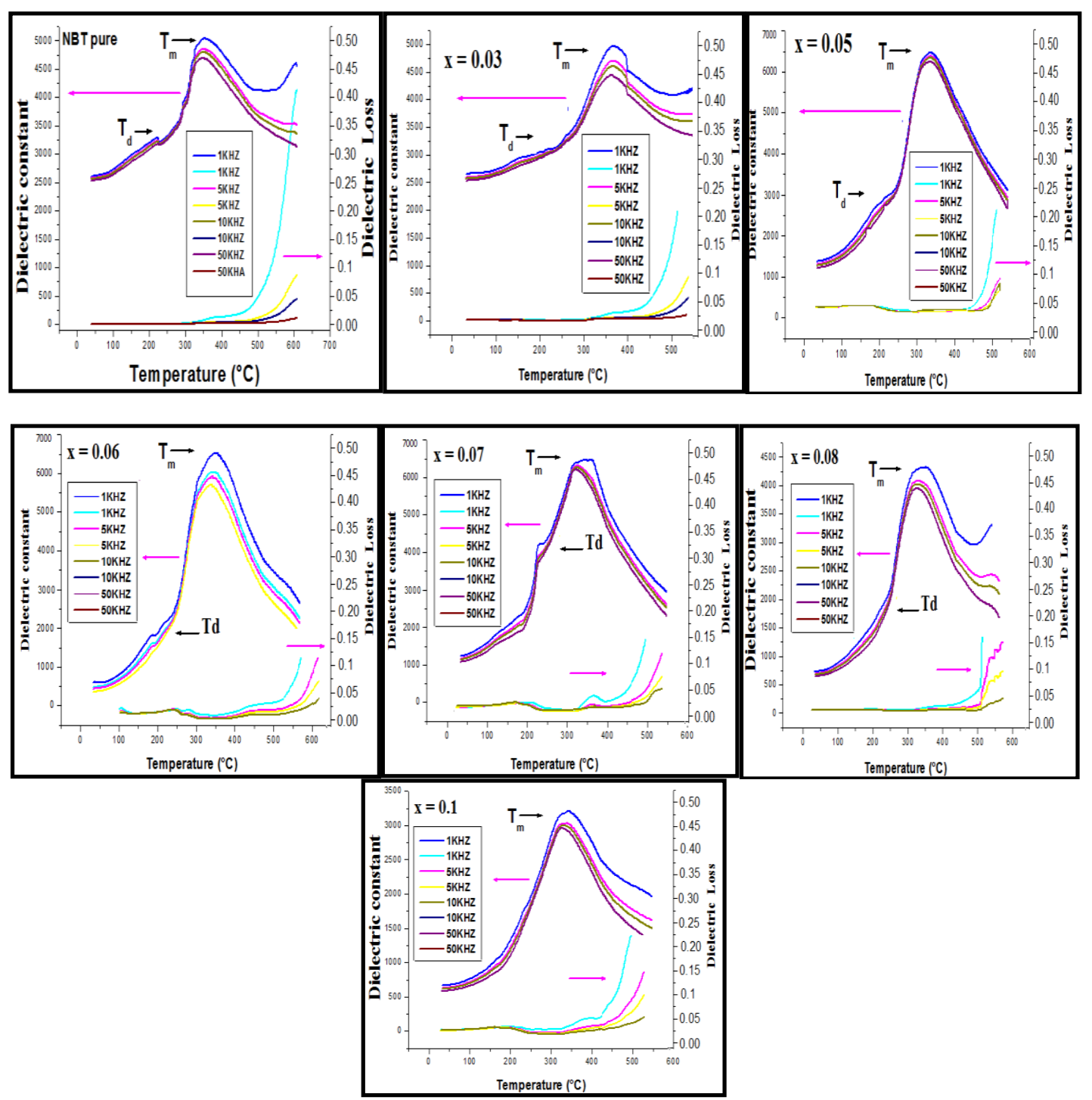

Figure 6. Temperature dependence of the dielectric constant and loss tangent (1-x) $\left(\mathrm{Na}_{0.5} \mathrm{Bi}_{0.5}\right) \mathrm{TiO}_{3}-\mathrm{xBaTiO}_{3}$ ceramics

Moreover, the first dielectric anomaly was located at the temperature of $(\mathrm{Td})$ (about $220^{\circ} \mathrm{C}$ at $1 \mathrm{KHz}$ ) and the second dielectric anomaly was located at the temperature of $(\mathrm{Tm})$ (around $320^{\circ} \mathrm{C}$ at $1 \mathrm{KHz}$ ) which is defined as the temperature displaying maximum $\mathrm{Er}(\mathrm{T})$, corresponding to the ferroelectric-to-paraelectric phase transition. However, a pronounced diffuseness near (Tm) was observed in all compositions analyzed. It can be seen that both $\operatorname{Er}(\mathrm{Tm})$ and $(\tan \delta)$ are strongly frequency dependent and we find that dielectric permittivity increases as the concentration of $\mathrm{Ba}^{2+}$ increased and it is maximum for $\mathrm{x}=0.07$ (around $\mathrm{Er}(\mathrm{Tm}$ ) $=6740$ at $1 \mathrm{KHz}$ ), this increase in dielectric permittivity depends on an increase in the average grain size and maximum value attained for the grain size $4.12 \mu \mathrm{m}$ near the morphotropic phase boundary (MPB). The characteristics of the curves and their changes with the composition are consistent with previous studies. ${ }^{25}$ In order to better understand the diectric relaxation at the second anomaly; we defined a parameter $\Delta \mathrm{Er}$ dispersion to quantify the frequency dispersion with the formula reported by $\mathrm{Ma} . \mathrm{C}$ et al. ${ }^{26}$
$\Delta \varepsilon r_{\text {dispersion }}=E r(\mathrm{Tm}, \mathrm{Td}, 1 \mathrm{kHz})-\operatorname{Er}(\mathrm{Tm}, \mathrm{Td}, 1 \mathrm{MHz})$

From the curves $\Delta \varepsilon \mathrm{E}$ dispersion shown in Fig.7, it is clear that the frequency dispersion presents a maximum at (Td) and (Tm). The large $\Delta \varepsilon r_{\text {dispersion }}$ values of all the samples indicated a strong frequency dispersion at $(\mathrm{Tm})$ in $(1-\mathrm{x})\left(\mathrm{Na}_{0.5}\right.$ $\left.\mathrm{Bi}_{0.5}\right) \mathrm{TiO}_{3}-\mathrm{xBaTiO}_{3}$ ceramics. In addition, $\Delta \varepsilon \mathrm{r}$ dispersion kept growing with the increase of $\mathrm{BaTiO}_{3}$ contenent, which means a good strengthening of the frequency dispersive behavior. The significant frequency dispersion in the dielectric behavior seems to suggest diffuse transition characteristics 27 . Consequently, the dielectric dispersion and shifting of transition temperature towards the lower temperature side were observed with the increase of frequency indicating a relaxation behavior in the (1x) $\left(\mathrm{Na}_{0.5} \mathrm{Bi}_{0.5}\right) \mathrm{TiO}_{3}-\mathrm{xBaTiO}_{3}$ ceramics. The relaxation behavior in the present samples may be attributed to cationic disorder due the random occupation of A-site cation $\left(\mathrm{Na}^{+}\right.$or $\mathrm{Bi}^{3+}$ and $\left.\mathrm{Ba}^{2+}\right)$ with different ionic radii and valence states. 


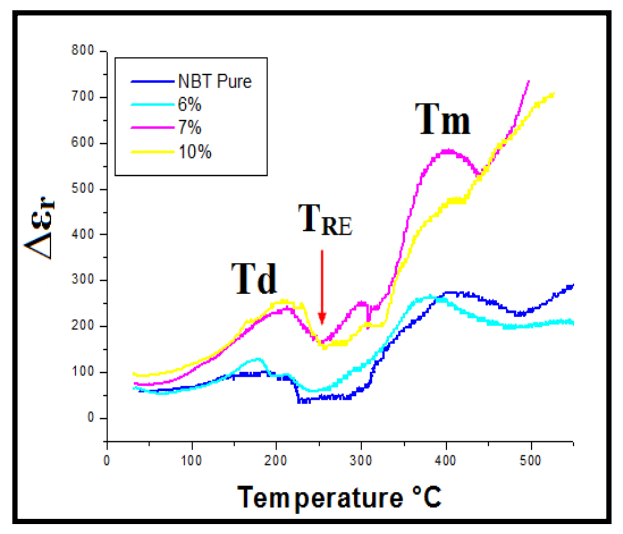

Figure 7. Temperature dependent $\Delta \varepsilon \mathrm{r}$ of $(1-\mathrm{x})\left(\mathrm{Na}_{0.5} \mathrm{Bi}_{0.5}\right) \mathrm{TiO}_{3}-\mathrm{xBaTiO}_{3}$ ceramics

Figure 8 shows the variation of real part of real $\mathrm{Z}^{*}$ with the frequency of various $(1-\mathrm{x})\left(\mathrm{Na}_{0.5} \mathrm{Bi}_{0.5}\right) \mathrm{TiO}_{3}-\mathrm{xBaTiO}_{3}$ ceramics with $\mathrm{x}$ $=0.05 ; 0.06$ and 0.07 at different temperature. As displayed in (Fig 8), the values of real $Z^{*}$ Increases brutally up to a certain limiting frequency $(\& 5 \mathrm{kHz})$, then progressively decreases and then, it becomes relatively frequency-independent. The decrease in real $\mathrm{Z}^{*}$ designates that the conduction is increasing with frequency. The higher values of real $\mathrm{Z}^{*}$ at lower frequencies indicate that the polarization in the ceramics is larger because at lower frequency all varieties of polarization are present. It is also remarked that the value of real $Z^{*}$ for all compositions corresponds at higher frequencies. The merger of real $\mathrm{Z}^{*}$ at higher frequencies indicates possible release of space charge polarization ${ }^{28}$.
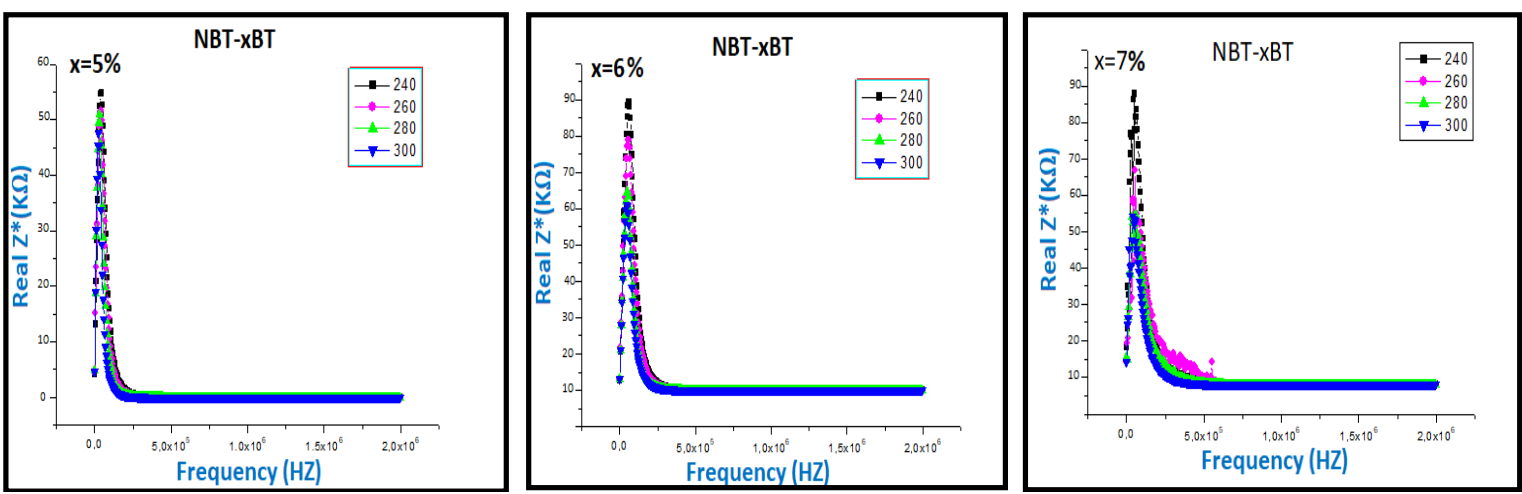

Figure 8. Variation of real $Z^{*}$ as a function of the frequency for $(1-\mathrm{x})\left(\mathrm{Na}_{0.5} \mathrm{Bi}_{0.5}\right) \mathrm{TiO}_{3}-\mathrm{xBaTiO}_{3}$ ceramics

Figure 9 shows the variation of imaginary part of Im $Z^{*}$ with frequency at various temperatures $(240-$ $300{ }^{0} \mathrm{C}$ ) for the composition with $\mathrm{x}=0.05 ; 0.06$ and 0.07 . The variation of $\operatorname{Im} Z^{*}$ with frequency presents a maximum for all samples at high frequencies. In addition, Im $\mathrm{Z}^{*}$ also decreases with increasing temperature due to the reduction of loss in the resistive part of the sample. It can be observed also that the curves exhibit broad and low-intensity peaks with a symmetrical shape. The broadening of the peak and half-widths of the peaks designate multiple relaxations and deviations from Debye behavior.
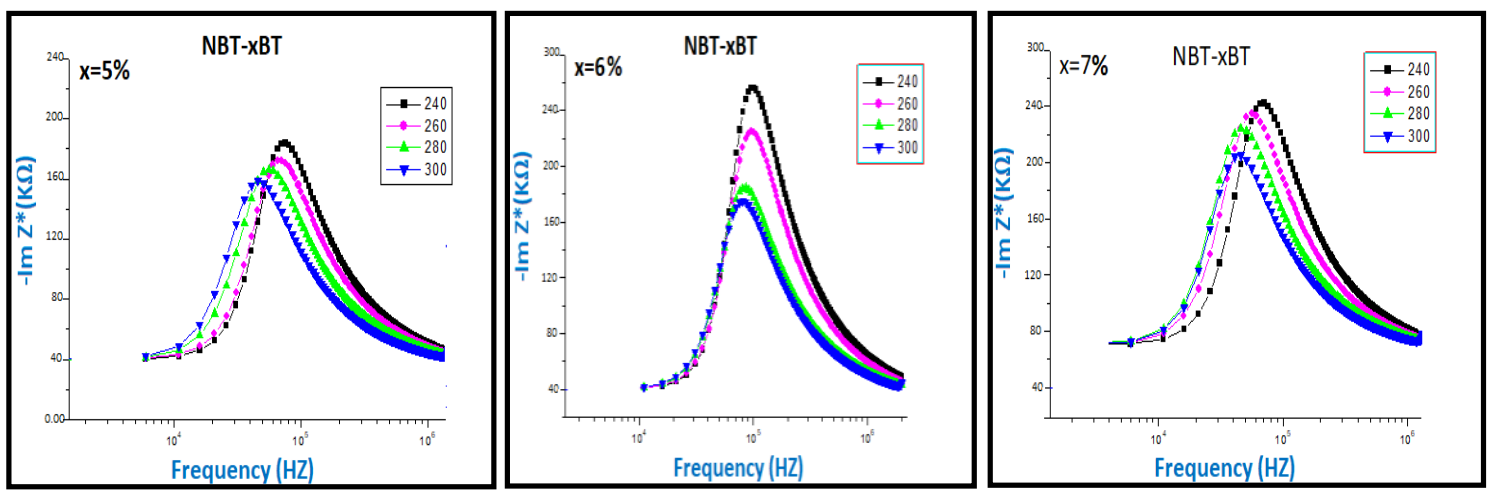

Figure 9. Variation of $\operatorname{Im} \mathrm{Z}^{*}$ as a function of the frequency for $(1-\mathrm{x})\left(\mathrm{Na}_{0.5} \mathrm{Bi}_{0.5}\right) \mathrm{TiO}_{3}-\mathrm{xBaTiO}_{3}$ ceramics 
Figure 10 shows the frequency dependences of the real $\mathrm{Z}^{*}$, and the $\mathrm{ImZ} \mathrm{Z}^{*}$, of the complex impedance at a temperature of in range $\left(240-300^{\circ} \mathrm{C}\right)$. The impedance spectrum is presented by semicircular arcs. The nature of variation of the arcs with temperature and frequency furnish various clues of the materials. The impedance spectra are characterized by the appearance of a single semicircular arc and the intercept of the semicircular arc with the real axis real $\mathrm{Z}^{*}$ gives us an estimate of the bulk resistance $(\mathrm{Rb})$ of the material. It has been remarked that the bulk resistance of the material decreases with increase in temperature noting a typical semiconducting property, i.e. temperature coefficient of resistance behavior. It is mentioned that with the increase in temperature the slope of the lines decreases and the lines bend towards real $\mathrm{Z}^{*}$ axis and at $300^{\circ} \mathrm{C}$; a semicircle could be traced, designating the increase in conductivity of all samples.
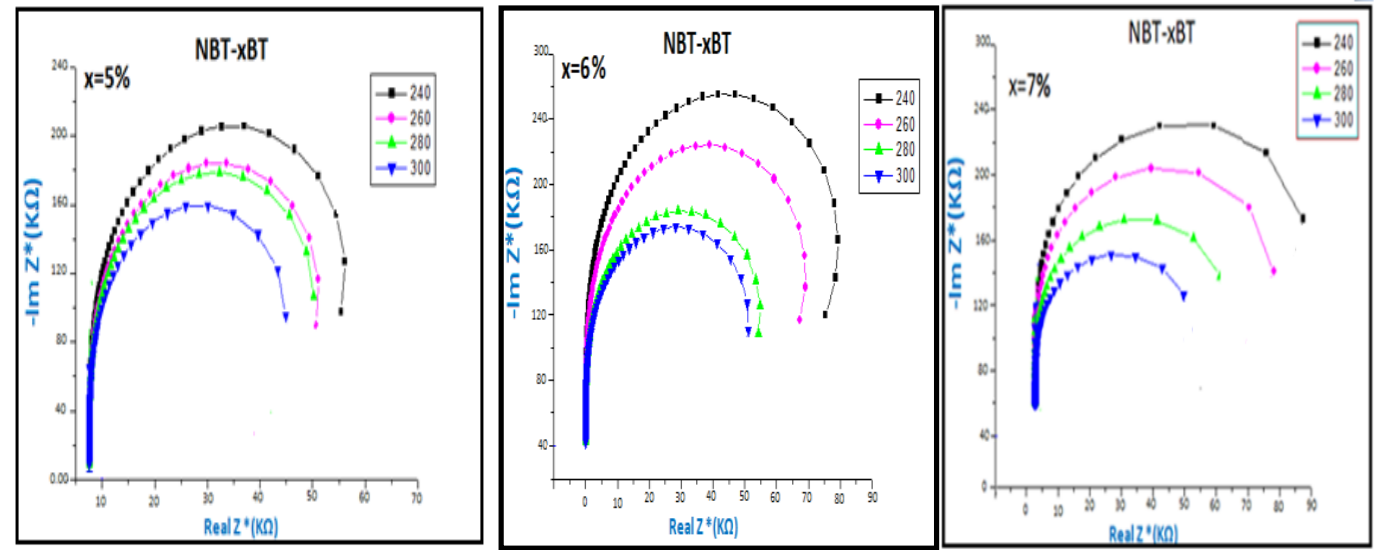

Figure 10. Complex impedance plots of the ceramics of $(1-\mathrm{x})\left(\mathrm{Na}_{0.5} \mathrm{Bi}_{0.5}\right) \mathrm{TiO}_{3}-\mathrm{xBaTiO}_{3}$

Figure 11 shows the permittivity as a function of frequency at different temperature for (1$\mathrm{x})\left(\mathrm{Na}_{0.5} \mathrm{Bi}_{0.5}\right) \mathrm{TiO}_{3}-\mathrm{xBaTiO}_{3}$ ceramics. Remarkable changes are observed in the value of permittivity dielectric with in-crease in frequency up to a certain frequency. With further increase in frequency, the value of $E r$ increased drastically, attaining a peak at a particular frequency depending on the Barium content and temperature. This peak frequency is known as resonant frequency (fr). With increase in frequency beyond the resonant frequency, the value of Er decreased sharply attaining a minimum value at a particular frequency called anti-resonant frequency (fa). These results are in good agreement with those

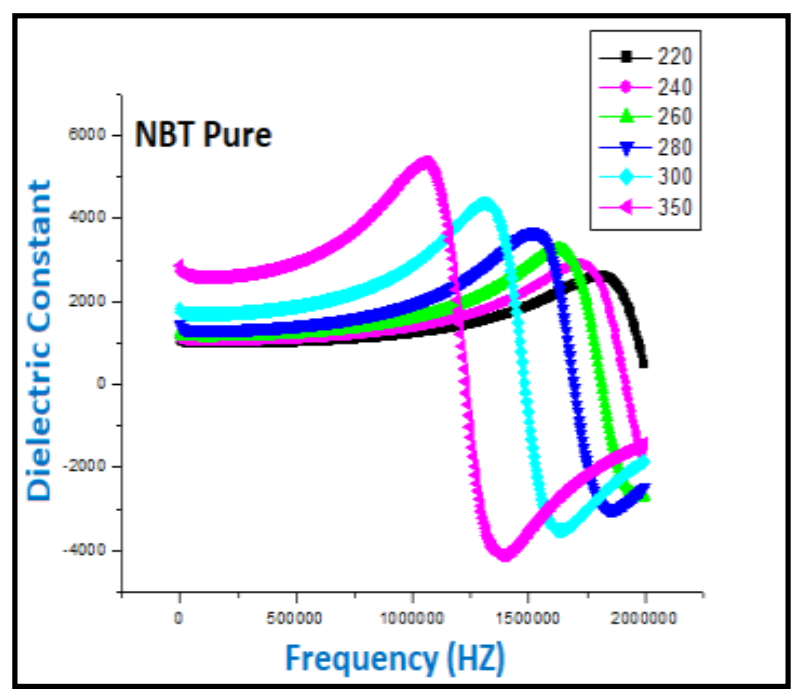

reported in the literature ${ }^{29,30}$. The values of resonant and anti-resonant frequencies are found to decrease according to the temperature up to $300^{\circ} \mathrm{C}$ and above $300^{\circ} \mathrm{C}$, the values increase in all samples. The values of dynamic electromechanical $K_{P}, K_{31}$ values are determined in radial mode employing the process proposed by Holland and Katiyar et al. ${ }^{31,32}$ based on Onoe's formulas ${ }^{33}$.

$\mathrm{K}_{\mathrm{p}}=\sqrt{\left[2.5\left(f_{a}-\frac{f_{r}}{f_{a}}\right)\right]}$

and

$\left.\mathrm{K}_{31}=\sqrt{\left[0.5(1-\sigma) \mathrm{K}_{\mathrm{P}}\right.}\right]$

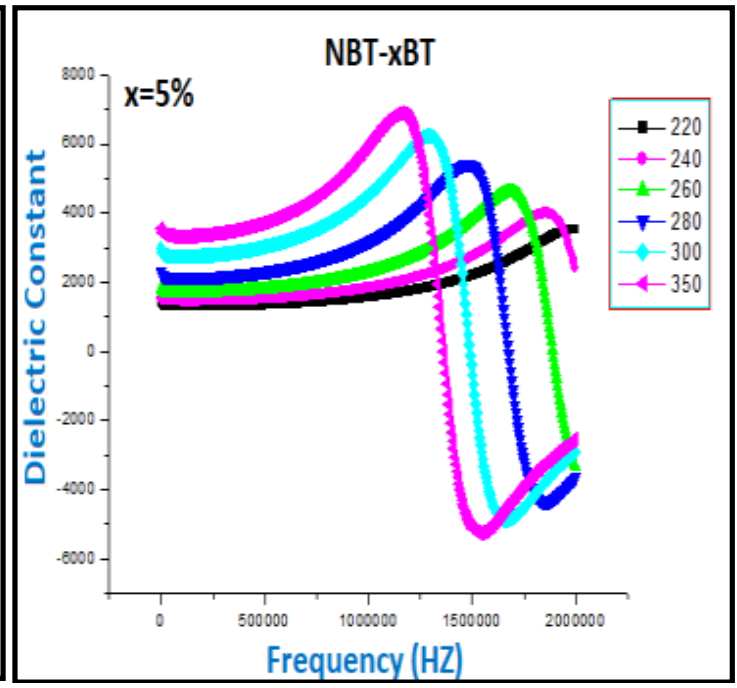



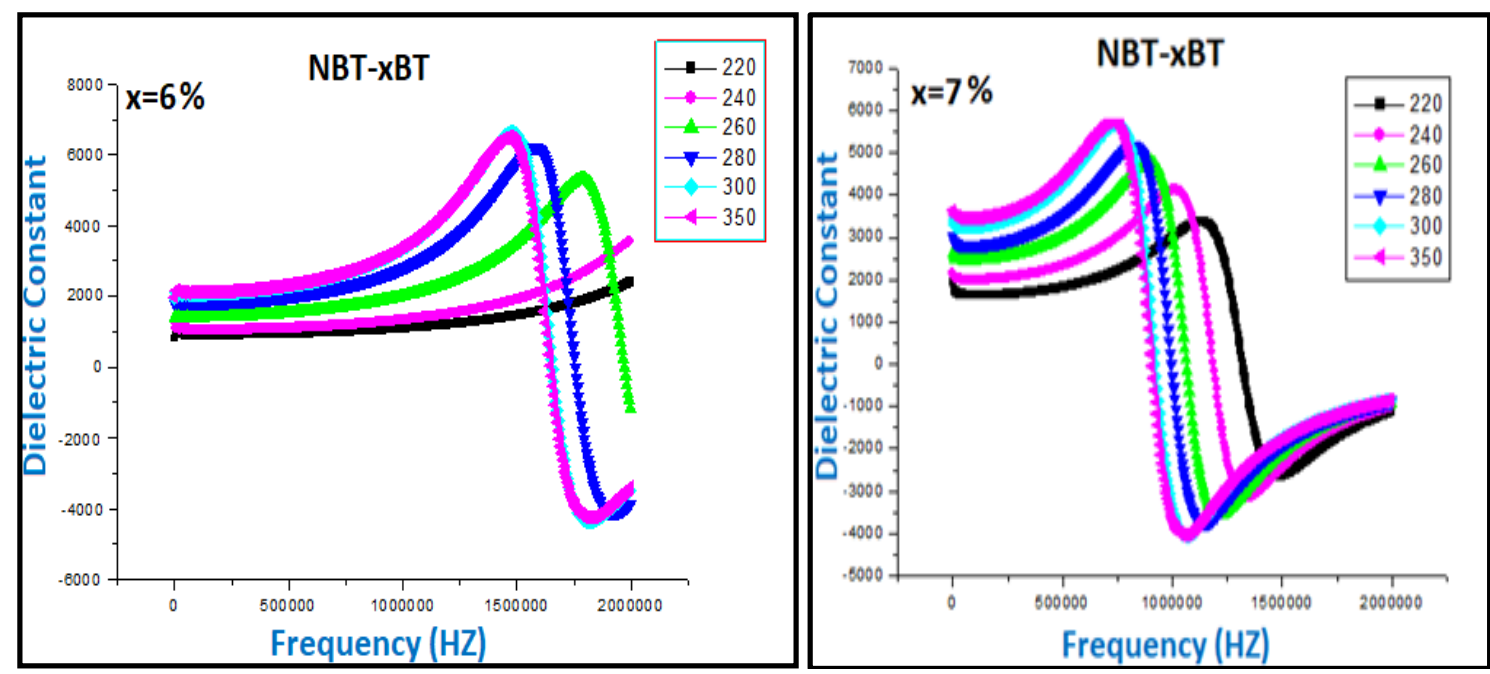

Figure 11. Evolution of the permittivity as a function of frequency at different temperature for $(1-\mathrm{x})\left(\mathrm{Na}_{0.5} \mathrm{Bi}_{0.5}\right) \mathrm{TiO}_{3}-\mathrm{xBaTiO}_{3}$ ceramics

$\sigma$ indicates the Poisson ratio and its value is 0.26 . Moreover, fr is Resonance frequency $(\mathrm{Hz})$ and $\mathrm{fa}$ is Anti-resonance frequency $(\mathrm{Hz})$. Electromechanical coupling coefficients are real numbers and their values depend on the mode of vibration. As mentioned in Fig.12. These values are influenced by dielectric losses and elastic losses. Barium doping grew the values of the electromechanical coupling coefficient. This increase may be associated with the increase in capacitance values. The variation in capacitance values may be explained by considering the relative sizes of Barium and bismuth ions. The radius of Barium ion is larger $\left(\mathrm{rBa}^{2+}=1.61 \AA\right)$, when compared to bismuth ion $\left(\mathrm{rBi}^{3+}=1.45 \AA\right) .{ }^{26}$
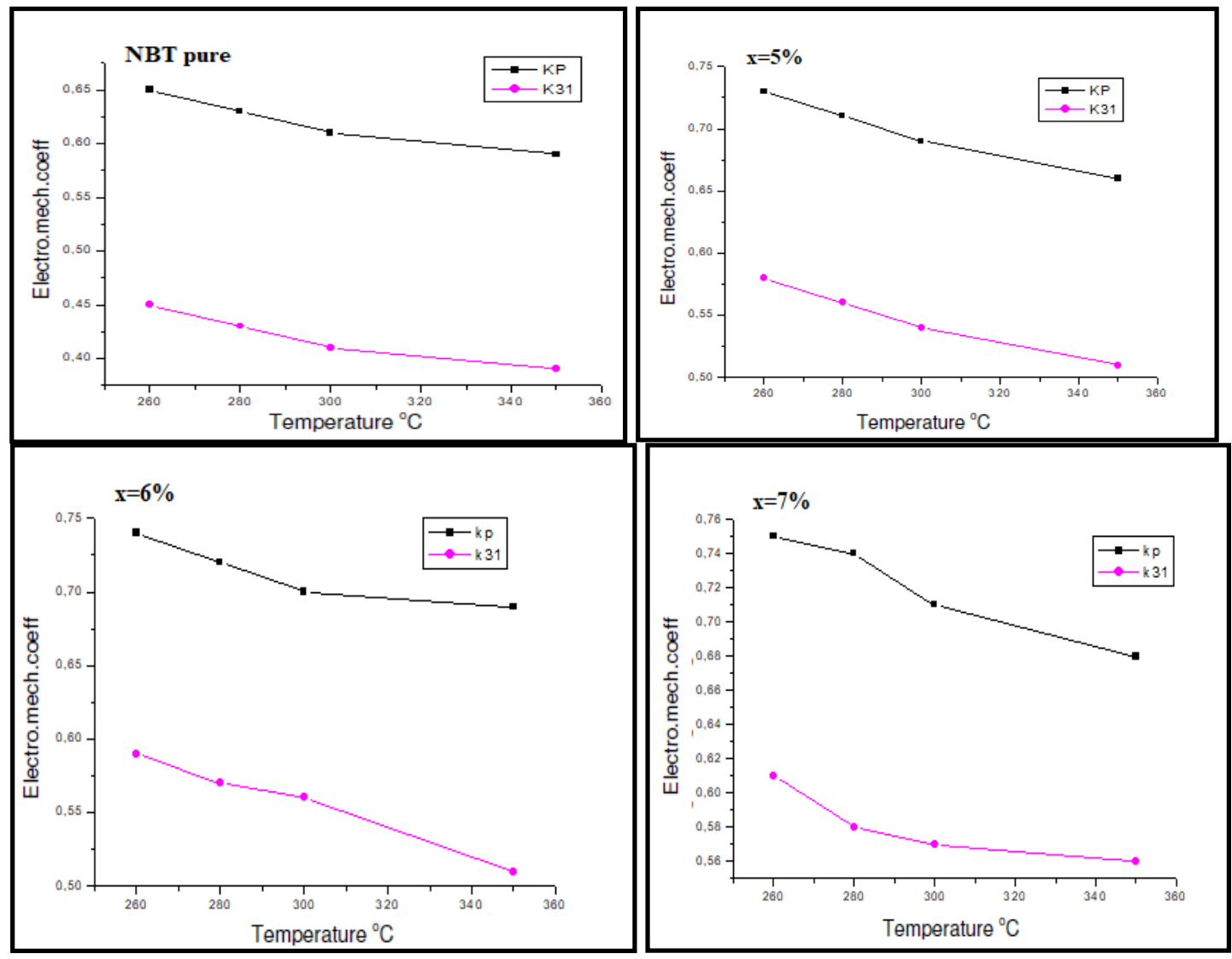

Figure 12. depicts the variation of $K_{P}$ and $K_{31}$ with temperature 


\section{Conclusion}

In summary, polycrystalline $(1-\mathrm{x})\left(\mathrm{Na}_{0.5} \mathrm{Bi}\right.$ $\left.{ }_{0.5}\right) \mathrm{TiO}_{3}-\mathrm{xBaTiO}_{3}(\mathrm{x}=0.00,0.03,0.05,0.06,0.07$, 0.08 and 0.10 ) ceramics were successfully prepared using conventional solid-state reaction technique. A morphotropic phase boundary (MPB) exists around at $x=0.05$ and $x=0.07$. The structure and dielectric properties were systematically investigated. The dielectric frequency dispersion at the two anomalies $\left(\mathrm{T}_{\mathrm{d}}\right.$ and $\left.\mathrm{T}_{\mathrm{m}}\right)$ were characterized by $\Delta \varepsilon \mathrm{r}$ dispersion $=\operatorname{Er}(\mathrm{Tm}, \mathrm{Td}, 1 \mathrm{kHz})-\varepsilon r(\mathrm{Tm}, \mathrm{Td}, 1 \mathrm{MHz})$, this ferroelectric diffuse behavior revealed can be attributed to cationic disorder due to the random occupation of A-site cations. The electromechanical coupling coefficients in radial mode $K_{P}$ and $K_{31}$ are calculated from the permittivity according to the frequency, thus the insertion of barium increases the value of $K_{P}$ and $K_{31}$. Complex impedance and colecole plots study reveal the existence of both grain and grain boundary contributions in (1$\mathrm{x})\left(\mathrm{Na}_{0.5} \mathrm{Bi}_{0.5}\right) \mathrm{TiO}_{3}-\mathrm{xBaTiO}_{3}$. An equivalent circuit has been proposed for the electrical response of the material.

\section{References}

1- J.Suchanicz, T.V.Kruzina, Dielectric properties thermal expansion and heat capacity of (1-x) Na0.5Bi0.5TiO3-xBaTiO3 single crystals $(x=0,0.02,0.025,0.0325$ and 0.05), Materials Science and Engineering, 2013, 178, 889-895.

2- M.Mesrar, T.Lamcharfi, N.Echatoui, F.Z.Ahjyaje, Hydrothermal Synthesis of Oxide and Carbonate Powders of (1-x) (Na0.5Bi0.5)TiO3-xBaTiO3 Ceramics Asian Journal of Chemistry, 2019, 31, 309-316.

3- B.Saradhi, K.Srinivas, T.Bhimasankaram, Impedanc And Modulus Spectroscopy Of (Na 1/2 Bi 1/2) 1-x Ca x TiO 3 Ceramics, International Journal of Modern Physics., 2002, 31, 4755-4766.

4- J.H.Cho, Y.H.Jeong, J.H.Nam, J.S.Yun, J.Y.Park, Phase transitio-nand piezoelectric properties of lead-free (Bi1/2Na1/2)TiO3BaTiO3 ceramics, Ceram Int., 2014, 40, 8419-8425.

5- G. O.Jones, P. A. Thomas. The tetragonal phase of $\mathrm{Na} 0.5 \mathrm{BiO}$. $5 \mathrm{TiO} 3$ a new variant of the perovskite structure, Acta Crystallographica Section B: Structural Science., 2000, 56, 426-430.

6- S.Sayyed, S.A.Shahin, Structural and dielectric anomalies near the MPB region of $\mathrm{Na} 0.5 \mathrm{Bi} 0.5 \mathrm{TiO} 3-\mathrm{SrTiO} 3$ solid solution, RSC Advances., 2015, 63, 50644-50654

7- H.M. Rietveld, A profile refinement method for nuclear and magnetic structures. Journal of applied Crystallo- graphy., 1969, 2, 65-71

8- J.R. MacDonald, Impedance Spectroscopy Emphasizing Solid Materials and Systems,
Wiley Interscience, John Wiley and Sons., 1987, 12, 1-346.

9- K.S. Rao, B. Tilak, K.C.V. Rajulu, A. Swathi, H.Workineh, A diffuse phase transition study on $\mathrm{Ba} 2+$ substituted $(\mathrm{Na} 0.5 \mathrm{Bi} 0.5) \mathrm{TiO} 3$ ferroelectric ceramic, J. Alloy. Compd., 2011, 509, 7121-7129.

10- K. Prasad, K. Kumari, K.P. Chandra, K.L. Yadav, Dielectric relaxation and ac conductivity of $\mathrm{WO}_{3}$ added $(\mathrm{Na} 1 / 2 \mathrm{Bi} 1 / 2) \mathrm{TiO} 3$ ceramic, Materials Science Poland., 2009, 27, 373-384.

11- H.Zhang, P.Xu, Preparation and enhanced electrical properties of grain-oriented (Bi1/2Na1/2)TiO3 based lead-free incipient piezo-ceramics, Journal of the European Ceramic Society., 2015, 35, 2501-2512.

12- M.Mesrar, T.Lamcharfi, N.Echatoui, F. Abdi, A.Harrach, Investigation of Morpho- tropic Phase Boundary by Rietveld Re-Finement and Raman Spectroscopy for $(1-\mathrm{x})(\mathrm{Na} 0.5$ Bi0.5)TiO3-xBaTiO3 Ceramics, Asian Journal of Chemistry, 2018, 30, 1012-1018.

13- R.Ranjan, A.Dviwedi, Structure and dielectric properties of ( $\mathrm{Na} 0.50 \mathrm{Bi} 0.50)$ xBaxTiO3: $0 \leq x \leq 0.10$. Solid state communications., 2005, 135, 394-399.

14- S.Joshi, S.Sayyed, S.Acharya, Percolation Effect of PZT-BNT Composite System on Sinterability and Dielectrics Behaviour in View of Development of LTCC, Ferroelectrics., 2015, 481, 155-165.

15- G.H.Kwei, A.C.Lawson, S.J.L.Billinge, Structures of the ferroelectric phases of barium titanate, The Journal of Physical Chemistry., 1993, 97, 2368-2377.

16- A.Neagu, C.W.Tai, Local disorder in $\mathrm{Na} 0.5$ $\mathrm{Bi} 0.5 \mathrm{TiO} 3$ piezoceramic determined by $3 \mathrm{D}$ electron diffuse scattering, Scientific reports., 2017, 7, 12519.

17- P.K.Tung, M.Major, J.Hudspeth, Compositional dependence of disordered structures in $\mathrm{Na}^{1} \frac{1}{2} \mathrm{Bi}^{1} \frac{1}{2} \mathrm{TiO} 3-\mathrm{BaTiO} 3$ solid solutions, Materials Research Bulletin., 2018, 106, 301-306.

18- E.Aksel, J.S.Forrester, J.C.Nino, Local atomic structure deviation from average structure of $\mathrm{Na}$ 0.5 Bi 0.5 TiO3: Combined x-ray and neutron total scattering study, Physical Review B., 2013, 87, 104113.

19- M.Gröting, K.Albe, Comparative study of A-site order in the lead-free bismuth titanates M1/2Bi1/2TiO3 (M= Li, Na, K, Rb, Cs, Ag, $\mathrm{Tl})$ from first-principles, Journal of Solid State Chemistry., 2014, 213, 138-144.

20- K.K. Mishra, V. Sivasubramanian, R.M. Sarguna, T.R. Ravindran, A.K. Arora, D.K. Aswal, A.K. Debnath, AIP Conf. Proc., 2010, $174,1313$.

21 - C.S.Devi, G.S.Kumar, G. Prasad, Control of ferroelectric phase transition in nano particulate NBT-BT based ceram- ics, 
Materials Science and Engineering: B., 2013, 178, 283-292.

22- M. K.Niranjan, T.Karthik, S.Asthana, J. Pan, Theoretical and experimental investigation of Raman modes, ferroelectric and dielectric properties of relaxor $\mathrm{Na} 0.5 \mathrm{BiO}$. 5TiO3, Journal of Applied Physics., 2013, 113, 194106.

23- K.Ramam, M.Lopez, Ferroelectric and piezoelectric properties of Ba modified lead zirconium titanate ceramics, Journal of Physics D: Applied Physics, 2006, 39, 4466.

24- C.Xu, D.Lin, K.W.Kwok, Structure, electrical properties and depolarization temperature of (Bi0. 5Na0. 5) TiO3-BaTiO3 lead-free piezoelectric ceramics, Solid state sciences., 2008, 10, 934-940.

25- Q.Xu, M.T.Lanagan, X.Huang, J.Xie, L.Zhang, H.Hao, Dielectric behavior and impedance spectroscopy in lead-free BNTBT-NBN perovskite ceramics for energy storage, Ceramics International., 2016, 42, 9728-9736.

26- C.Ma, X.Tan, E.Dul'Kin, M.Roth, Domain structure-dielectric property relationship in lead-free (1-x)(Bi 1/2 Na 1/2)TiO3-x BaTiO3 ceramics, Journal of applied physics, 2010, 108,104105

27- A.M.Balagurov, E.Yu.Koroleva, A.A. Naberezhnov, V.P.Sakhnenko, The rhombohedral phase with incommensurate modulation in $\mathrm{Na} 1 / 2 \mathrm{Bi} 1 / 2 \mathrm{TiO} 3$, Phase Transitions., 2006, 79, 163-173.

28- B.Behera, P.Nayak, R.N.Choudhary, Structural and electrical properties of $\mathrm{KCa} 2$ Nb5O15 ceramics, Central European Journal of Physics., 2008, 6, 289-295.

29- S.R.Kanuru, K.Baskar, R.Dhanasekaran, Synthesis, structural, morphological and electrical properties of NBT-BT ceramics for piezoelectric applications, Ceramics International, 2016, 5, 6054-6064.

30- C.S. Devi, G.S.Kumar, G. Prasad, Control of ferroelectric phase transition in nano particulate NBT-BT based ceramics, Mater. Sci. Eng. B., 2013, 178, 283-292.

31- V.K.Katiyar, S.Z.Srivastava, J.Singh, Dielectric and piezoelectric properties of lead zirconate titanate doped with chromium oxide, Journal of applied physics., 1994, 76, 455-465.

32- H. Richard, IEEE Trans. Sonics and UltraSonics., 1969, 173, 16.

33- M.Onoe, H.Jumonji, Useful formulas for piezoelectric ceramic resonators and their application to measurement of parameters, The Journal of the Acoustical Society of America, 1967, 41, 974-980. 